Brit. J. prev. soc. Med. (1976), 30, 268-272

\title{
Detection and treatment of hypertension in an inner London community
}

\author{
RICHARD F. HELLER \\ Lecturer in Epidemiology. St Mary's Hospital Medical School
}

\begin{abstract}
Heller, R. F. (1976). British Journal of Preventive and Social Medicine, 30, 268-272. Detection and treatment of hypertension in an inner London community. A postal survey of a random sample of the population living near St Mary's Hospital, Paddington was taken to determine earlier experience in these people of blood pressure measurement and treatment. Eighty-five per cent of those who could return their questionnaires did so; eighty per cent of the respondents said they had had their blood pressure measured in the past, and $60 \%$ reported such a measurement during the previous three years. The respondents aged between 40 and 59 years were invited for a blood pressure screening measurement and $52 \%$ responded. Seventy-seven per cent of those found to be hypertensive on screening (systolic $\geq 160 \mathrm{mmHg}$ and/or diastolic $\geq 100 \mathrm{mmHg}$ ) said they had had their blood pressure measured during the preceding three years. The reason for the poor control of hypertension in a community, therefore, is more likely to be a failure of doctors to take action on hypertension than a failure to detect it in the first place.
\end{abstract}

Despite the risks of having a raised blood pressure (Society of Actuaries, 1959; Kannel and Dawber, 1973) and the known benefits of its reduction (Veterans Administration Study Group, 1967, 1970) population surveys have indicated that in most cases hypertension is either untreated or inadequately treated. Five separate studies in the United States of America indicated that between $11 \%$ and $23 \%$ of the hypertensive population had their blood pressure adequately controlled (Schoenberger et al., 1972; Wilber, 1973; Henderson et al., 1974). Unpublished data from a large trial of coronary heart disease among middle-aged men in industry in the UK (WHO Collaborative Group, 1974) suggest that only $7 \%$ of the hypertensive population is adequately controlled to below $100 \mathrm{mmHg}$ diastolic. This increases to $29 \%$ when control is defined as a diastolic pressure on treatment of less than $110 \mathrm{mmHg}$. As part of an attempt to find the reasons for this poor control, a postal survey was undertaken to ask members of a random sample of the general population if they had had their blood pressure measured in the past. If few members of a population had had a blood pressure measurement the reason for the poor control would be a failure of detection of hypertension. If the majority had had their blood pressure measured then the reason for poor control would be a failure of action on detected hypertension, and this would be of importance in planning corrective measures.

As an additional part of the study a screening survey (among respondents to the postal questionnaire) was performed to assess the part it could play in detecting hypertension in the community.

\section{Postal Survey}

\section{MeTHODS}

A questionnaire was sent by post to a sample of $\frac{D}{2}$ the population living in the catchment area of St Mary's Hospital, Paddington. A $1.5 \%$ random $N$ sample was drawn from the Electoral Register, identifying 1143 adults. In addition to the question- 0 naire each subject received an explanatory letter and $\mathrm{\omega}$ a stamped addressed envelope. The questionnaire included the question 'Have you ever had your bloodo pressure measured?' If the answer was positive the $\Phi$ subjects were asked to state when, by whom, and if ${ }^{\text {? }}$ 
they had ever been told they had a raised blood pressure and been given treatment for it. A diagram was drawn on the form in case there should be any doubt about what a blood pressure measurement was. The subjects were also asked what medical contact they had had during the previous three years. Those who had not replied after 12 days were sent a reminder letter which included a copy of the original letter and questionnaire and another stamped addressed envelope. Those who still had not replied after 29 days were similarly sent a second reminder.

\section{SCREENING SURVEY}

The subjects aged between 40 and 59 years who had returned a questionnaire were placed at random into one of two groups. Those in the first group were asked to visit their general practitioner, and those in the second to come to St Mary's Hospital for a blood pressure measurement. A letter was written to each person explaining the need for blood pressure screening, the letters differing only in the instructions of where to go. Those who were asked to visit their general practitioner had a letter to give him asking him to measure the blood pressure and send the result to the author in an enclosed stamped addressed envelope. If no reply was received after four weeks a reminder letter was posted to the subject. Those asked to come to the hospital were sent an appointment card with a specified time (but with a wide choice if this time was not convenient) and a map of the Epidemiology Department where the measurements were to take place. Those who did not attend were sent a second letter. Blood pressures were measured (by the author) using a Hawksley random zero machine. Those whose initial pressure was $\geq 160 \mathrm{mmHg}$ systolic and/or $\geq 100 \mathrm{mmHg}$ diastolic had a second reading, and if the mean was at or above these cut-off points the subject was told his blood pressure was slightly raised and asked if he wanted his general practitioner to be informed. If he did, he was asked to see his general practitioner who would in the meantime have received an explanatory letter. Three months later the general practitioners were asked if the person had visited and whether treatment had started.

Any subject who had shown anxiety about hypertension on the questionnaire was excluded before randomization which was performed on 264 of the original respondents. Of these 133 were referred to their general practitioner and 131 asked to attend St Mary's Hospital. The answers to the questionnaires showed that randomization had produced similar groups in all respects except that the hospital subjects comprised relatively more males.

\section{Postal Survey}

\section{RESUlts}

The Response Completed questionnaires were received from 861 people, $75 \%$ of the total (crude response rate) and $85 \%$ of those who could have replied (corrected response rate). Of the 1143 forms, 127 were returned either by the Post Office or by other people living at the addresses to which the letters had been sent, stating that the subject had moved, died, or was too ill to reply. It appeared that the first reminder letter had boosted the response but that the second letter had had little effect. A follow-up of a sample of one-in-four of the people from whom nothing had been heard showed that $42 \%$ did not reply because they had died, were ill, or had changed their address.

AnSWERS To THE QUeSTIONNAIRE Sixty per cent of all the respondents stated that they had had their blood pressure measured during the previous three years, and as many as $80 \%$ (690 of the 861 respondents) reported a blood pressure measurement at some time in the past. Table I shows that women were more likely to report a blood pressure measurement than men. Of the 690 respondents who recalled a previous blood pressure measurement the most recent measurement had been made at a

TABLE I

PROPORTION REPORTING A BLOOD PRESSURE MEASUREMENT (POSTAL QUESTIONNAIRE)

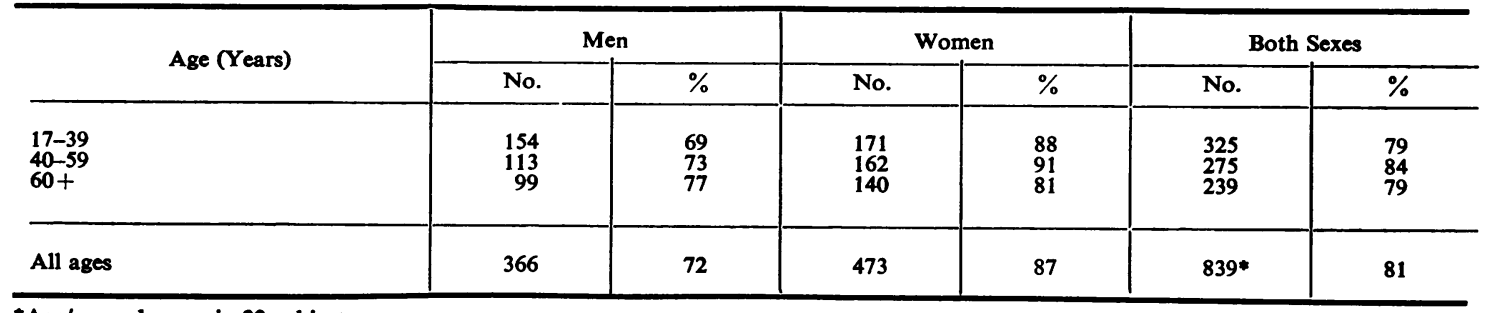

*Age/sex unknown in 22 subjects. 
hospital in $51 \%$, at a general practitioner's surgery in $36 \%$, and at work in 3\% (the remainder being made up by $6 \%$ 'elsewhere' and $4 \%$ who did not remember). Insurance or pre-employment medical examinations accounted for $21 \%$ of the recent measurements in men as did antenatal or family planning visits in $24 \%$ of the women.

Sixteen per cent of the respondents had been told at some time that their blood pressure was raised, $7 \%$ had received treatment, and $3 \%$ were currently on treatment for a raised blood pressure. Older people were more likely to report knowledge of and treatment for hypertension (Table II). Of those on treatment for hypertension at the time of the survey $68 \%$ were aged 60 or more.

\section{TABLE II}

REPORTED KNOWLEDGE OF AND TREATMENT FOR HYPERTENSION (POSTAL QUESTIONNAIRE)

\begin{tabular}{l|c|c|c|c}
\hline & & \multicolumn{3}{|c}{ Raised Blood Pressure } \\
\hline Age (Years) & No. & $\begin{array}{c}\text { \% Ever } \\
\text { Told }\end{array}$ & $\begin{array}{r}\text { \% Ever } \\
\text { Treated }\end{array}$ & $\begin{array}{c}\text { \% On } \\
\text { Treatment }\end{array}$ \\
\hline $17-39$ & 325 & 13 & 4 & 1 \\
$40-59$ & 276 & 17 & 5 & 2 \\
$60+$ & 239 & 19 & 13 & 8 \\
\hline All ages & $840^{*}$ & 16 & 7 & 3 \\
\hline
\end{tabular}

*Age unknown for 21 subjects.

Only $18 \%$ of the respondents said they had had no medical contact in the previous three years. Altogether $73 \%$ stated that they had made contact with their general practitioner, $48 \%$ had visited a hospital outpatient or casualty department, and $26 \%$ had been hospital inpatients during the previous three years.

QUestionnaire Validation Studies performed to validate the answers to the questionnaire included comparison with answers at subsequent interview (during screening), a study of duplicate replies, and a separate study in which identical questionnaires were posted and the replies compared with information previously recorded from general practice notes. These indicated that three of the questions might have produced underestimates. The proportion of the population with an earlier blood pressure measurement was more likely to be $86 \%$ than $80 \%$, the proportion on treatment for a raised blood pressure $4 \%$ instead of $3 \%$, and the proportion who had visited their general practitioner in the previous three years as high as $92 \%$ instead of the $76 \%$ in the main study.

\section{SCREENING SURVEY}

Response to THE SCREening InVITATION The overall response rate was $52 \%$. Altogether 72 of the $133(54 \%)$ responded to the request to visit their general practitioner and 65 of the $131(50 \%)$ responded to the hospital invitation.

Those who had responded early to the questionnaire were more likely to come for screening as were those who indicated on their questionnaires that they had had medical contact in the previous three years (Table III). Factors such as age, sex, or previous experience of blood pressure measurement and treatment made no difference to the tendency to come for screening, either to hospital or a general practitioner.

\section{TABLE III}

MEDICAL CONTACT IN THREE YEARS OF THOSE SCREENED AND THOSE INVITED BUT NOT SCREENED

\begin{tabular}{l|c|c}
\hline Medical Contact in Three Years* & $\begin{array}{c}\text { Came for } \\
\text { Screening } \\
\% \\
\text { (No. }=137)\end{array}$ & $\begin{array}{c}\text { Invited but } \\
\text { Not Screened } \\
\text { (No. \% 127) }\end{array}$ \\
\hline $\begin{array}{c}\text { General practitioner } \\
\text { Hospital }\end{array}$ & 78 & $66^{* *}$ \\
Outpatient or casualty department & 54 & $39 * *$ \\
Inpatient & 23 & 24 \\
No medical contact & 10 & $28^{* *}$ \\
\hline
\end{tabular}

*According to answers to postal questionnaire.

**Differences between screened and not screened significant $P<0.05$. Figures are percentages of number in each column.

HYPERTENSION Of the 137 people screened, 31 were hypertensive (defined as systolic $\geq 160 \mathrm{mmHg}$ and/or diastolic $\geq 100 \mathrm{mmHg}$ on the first reading). The prevalence of hypertension was the same in men and women and although both systolic and diastolic pressures were higher when measured in hospital than by the general practitioner the differences were not significant. (Of the 31 hypertensive subjects, 15 came from the general practice and 16 from the hospital side of the screening survey.)

The questionnaire replies (Table IV) showed that of those found to be hypertensive, $77 \%$ said they had had their blood pressure measured during the previous three years. This is significantly more than the $49 \%$ of the normotensives who reported such a measurement $(P<0 \cdot 05)$. Of the hypertensive subjects $42 \%$ said they had been told before that their blood pressure was raised.

Twelve people from the hospital screening were referred to their general practitioner because of 
TABLE IV

EARLIER BLOOD PRESSURE EXPERIENCE* ACCORDING TO BLOOD PRESSURE ON SCREENING

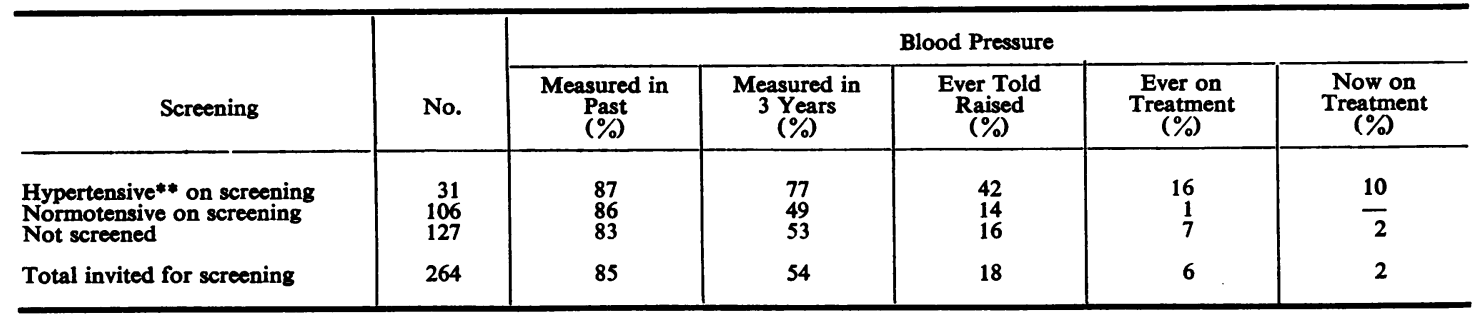

*According to answers to postal questionnaire.

* Systolic $\geq 160 \mathrm{mmHg}$ and/or diastolic $\geq 100 \mathrm{mmHg}$.

hypertension. By three months, seven of the 12 had been to see their general practitioner-two were already on treatment and three were started on treatment as a result of the visit. So of 10 'new' hypertensives five visited and three began treatment.

\section{Discussion}

The response rate to the postal survey was encouraging and together with the validation studies suggests that this is a good way of obtaining medical information in this part of London. The finding that at least $80 \%$ of a general population sample have had their blood pressure measured in the past, $60 \%$ in the previous three years, is information which does not seem to have been obtained before in this country. This suggests that most of the hypertension in the community is known about and that a failure of detection is not the main cause for its poor control. The results of the screening survey re-emphasize this point in that $77 \%$ of those found to be hypertensive reported a blood pressure measurement during the previous three years. (A Canadian Survey (Sackett, 1975 personal communication) similarly found that $71 \%$ of the discovered hypertensives had had a blood pressure measurement during the preceding two years.) In fact, only $42 \%$ of those hypertensive at screening had previously been told that they had a raised blood pressure. It is unlikely that the hypertension had developed since the last measurement (Kannel and Dawber, 1973), but possible that the screening level was higher than before due to the considerable variability of blood pressure (vide infra). It appears more likely that the subjects had, for one reason or another, not been previously informed of a raised measurement. Most of those hypertensive on screening, even if they had previously been told of a raised blood pressure, had not been treated (the validation studies implying only a small underestimate in answer to the question about such treatment).
Table IV shows that, conversely, some subjects who were normotensive on screening had previously been told that their blood pressure was raised. The use of a single examination to classify a subject as 'hypertensive' or 'normotensive' was studied by Armitage et al. (1966) who found that this could produce more than one-third false positives and $5 \%$ false negatives due to the considerable within-subject variability of blood pressure. The subjects in the current survey who said they had previously been told that they were hypertensive but who fell below the screening cut-off point may fall into the false negative group mentioned by Armitage, or the information may have been based on different criteria to define hypertension. It does not appear that anti-hypertensive treatment was being given to these people and, although the question was difficult to validate, it has at least some accuracy since a greater proportion of those hypertensive on screening said they had been told of hypertension in the past than those found to be normotensive.

The response to the request for screening was disappointing with only half of those contacted actually attending. Large scale population screening for hypertension has been found to produce much larger response rates-even up to $95 \%$ (Miall and Chinn, 1974). Methods have included widespread publicity to encourage group response and home visiting. Wilber et al. (1972) found that home visiting produced a better response than an invitation to a hospital or health centre. Hypertension screening surveys in which general practitioners have written to their own patients to invite them for screening have also produced high response rates of $75 \%$ and 86\% (Adler and Marson, 1973; Coope, 1974). The current survey could not match the response rates produced by these other methods, and the people who did attend tended to have had recent medical contact in any case. 
The final yield of the hospital part of the screening survey was that three people were treated out of 131 invited for screening (no attempt was made to assess whether those screened by the general practitioners were started on treatment). While this was a lower yield than anticipated it means that the screening process was probably worthwhile. However, two of these three subjects who were started on treatment had had a blood pressure measurement during the preceding three years and the other had been told her blood pressure was raised 10 years earlier.

\section{CONCLUSIONS}

The screening survey performed in this study produced an unsatisfactory response and would have been largely unnecessary if adequate action had been taken on the hypertension that must previously have been detected. Screening surveys, however, remain necessary to detect the hypertension of the few people who do not otherwise make medical contact (if ways can be found to attract them to the screening process). For most people, however, screening during routine medical contact would be sufficient for detectionand this is apparently happening now since so many of the postal survey respondents reported having had their blood pressure measured. The problem appears to lie in persuading doctors to start treatment on the hypertension they detect. Doctor education programmes have been suggested in the USA (Stokes, Payne, and Cooper, 1973; Cheitlin, 1974) and if appropriate guidelines could be devised these might prove a valuable way of improving the control of hypertension in the community.

I thank Professor G. A. Rose for his help and encouragement, and the St Mary's Hospital Joint Standing Research Committee for financial assistance.

Requests for reprints: R. F. Heller, MB, MRCP, Epidemiology Department, St Mary's Hospital Medical School, Praed Street, London W2 1NY.

\section{REFERENCES}

ADleR, M. W. and MARson, W. S. (1973). Randomized controlled trial of treatment of moderate hypertension in general practice: a feasibility study. Proc. roy. Soc. Med., 66, 1012.
Armitage, P., Fox, W., Rose, G. A., and Tinker, C. MP (1966). The variability of measurements of casuas BP. II, Survey experience. Clin. Sci., 30, 337.

CHEIrLIN, M. D. (1974). The physician and hypertension J. Amer. med. Ass., 288, 1249.

COOPE, J. (1974). A screening clinic for hypertension if general practice. J. roy. Coll. gen. Practit., 24, 161. $\overline{\frac{D}{D}}$

Henderson, M., Apostolides, A., Entwisle, G., an Hebel, R. (1974). A study of hypertension in a blacf urban community: preliminary epidemiological findo ings. Prev. Med., 3, 334.

KANNEL, W. B. and DAWBER, T. R. (1973). Hypertensive cardiovascular disease: the Framingham study. Infw Hypertension: Mechanisms and Management, edited bo G. Onesti, K. E. Kim, and J. J. Moyer, pp. 93-11@ Grune and Stratton, New York.

Miall, W. E. and ChINN, S. (1974). Screening foo hypertension: some epidemiological observations Brit. med. J., 3, 595.

Schomnberger, J. A., Stamler, J., Shekelle, R. BO and SHEKELLE, S. (1972). Current status of hypertens;on. control in an industrial population. J. Amer. med. 222, 559.

Society of Actuaries (1959). Build and Blood Pres: Study, vols I and II. Chicago.

Stokes, J. B., Payne, G. H., and Cooper, T. (19\&3) Hypertension control-the challenge of patif education. New Engl. J. Med., 289, 1369.

Veterans Administration Study Group on ANTE HYPERTENSIVE AGENTS (1967). Effects of treatment or morbidity in hypertension. Results in patients witf blood pressures averaging 115 through $129 \mathrm{mmH}$ J. Amer. med. Ass., 202, 116.

(1970). Effects of treatment on morbidity in hyper tension. II. Results in patients with diastolic bloog pressures averaging 90 through $114 \mathrm{mmHg}$. J. Ames med. Ass., 213, 1143.

WiLBER, J. A. (1973). The problem of undetected andi. untreated hypertension in the community. Buts N.Y. Acad. Med., 49, 510.

- Millward, D., Baldwin, A., Capron, B⿳亠丷厂 Silverman, D., James, L. M., Wolbert, T., and McCombs, N. J. (1972). Atlanta community high bloog pressure program methods of community hypertensio screening. Circulation Res., 31 (suppl. 2), 101.

World Health Organization Collaborative Groue (1974). An international controlled trial in the. multifactorial prevention of coronary heart diseasef Int. J. Epidemiol., 3, 219. 